\section{Anatomical Evidence for a Counter- current Heat Exchanger in the Leatherback Turtle (Dermochelys coriacea)}

FraIr et al. ${ }^{1}$ have recently given strong circumstantial evidence that leatherback turtles (Dermochelys coriacea) can maintain a deep body temperature at least $18^{\circ} \mathrm{C}$ higher than the ambient temperature of cold water. The mechanisms underlying this differential are largely unknown but are presumed to be muscular activity combined with the thermal inertia of a large body mass and an insulating layer of subepidermal fat ${ }^{1}$. Countercurrent flows have also been suspected as a heat retention mechanism ${ }^{1-2}$ but so far have not been proved. We now present anatomical evidence for a countercurrent heat exchanger in the front and rear flippers of a leatherback turtle, which is the first evidence for this kind of heat retention mechanism in a reptile.

The countercurrent system was discovered during a general dissection of a female leatherback (in preparation) that had recently died in the New England Aquarium after being in captivity for approximately 6 days. The specimen had been captured by Mr Charles Stowe, jun., in 12 fathom of water off Matinicus in the Gulf of Maine on July 28, 1972. Three days after capture the specimen was transported to the aquarium but, as is usual with these turtles, it fared poorly in captivity; plans had been made to release it on the day it died. The specimen weighed 625 pound $(284 \mathrm{~kg})$ and had a straight line carapace length of 54 inch $(137 \mathrm{~cm})$. Before dissection the turtle had been in the New England Aquarium freezer at approximately $-15.5^{\circ} \mathrm{C}$ for $30 \mathrm{~d}$.

The countercurrent heat exchanger consists of a single welldefined bundle of closely packed veins and arteries which we intercepted near the junction with the body in each of the front and rear flippers. The bundles tend to be deeper than broad and can be readily separated from the surrounding muscle. In the front flipper the bundle ran just posterior and ventral to the humerus and measured approximately $35 \times 20 \mathrm{~mm}$ at the distal end of the humerus; in the rear flipper the bundle ran just dorsal to the femur and was smaller, measuring $25 \times 13 \mathrm{~mm}$ at the proximal end of the femur. In gross cross section the veins had collapsed and were difficult to see; the arteries, however, stood out clearly and all seemed to be approximately the same size.

We prepared histological sections from excised pieces of the bundles in all four appendages (Figs 1 and 2) and counted the veins and arteries in each section; the ratio of veins to arteries

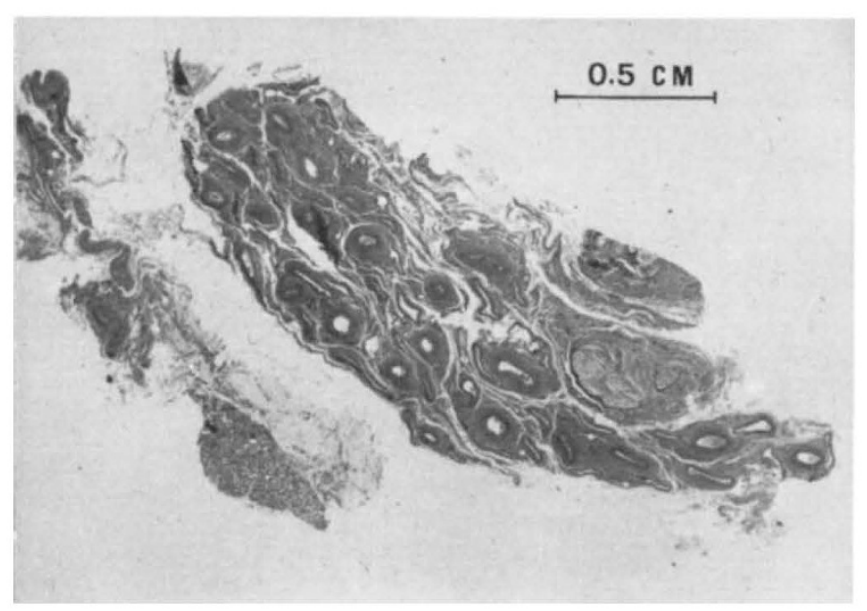

Fig. 1 Cross-section of the vascular bundle in the left rear flipper at the level of the proximal end of the femur. The veins have collapsed but the arteries have maintained their shape.

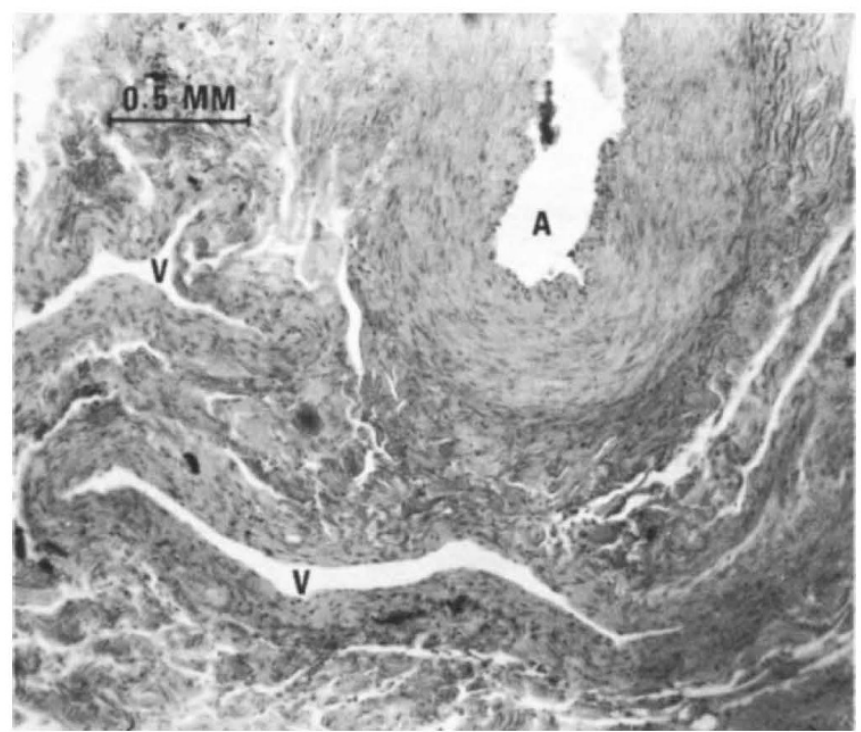

Fig. 2 Detailed view of an artery (A) and two veins (V) in a histological cross-section of the vascular bundle in the left rear flipper at the level of the proximal end of the femur.

in the sections varied from $1.75: 1$ to $4.2: 1$ (average $=2.7: 1$ ) with no significant difference $\left(\chi^{2}, P>0.05\right)$ between the ratios of any two sections. The maximum number of veins and arteries counted in a complete cross-section from a bundle in the front (right) flipper was seventy-eight and twenty-six respectively and the maximum number for a similar section in the rear (left) flipper was forty-eight and nineteen. These figures probably very nearly represent the complete complement of veins and arteries in the bundles at the base of the respective flippers. In the histological sections veins and arteries seemed to be scattered more or less randomly, and there was no evidence of any unit structure to the veins and arteries within the bundles.

Our knowledge of leatherback turtles now shows that they, of all the reptiles, are the most similar to the homoeothermous birds and mammals in their thermal biology: not only can they generate a striking temperature differential between their body core and the external environment in the absence of an external heat source ${ }^{1}$, but they have, uniquely for reptiles, the two classic adaptations of birds and mammals for retaining body heat, namely, an insulating layer of subepidermal fat and a countercurrent heat exchanger.

We thank L. B. Garibaldi of the New England Aquarium for making the turtle available and A. F. Bennett, P. K. Greer, R. Huey, C. R. Taylor, P. E. Vanzolini and E. E. Williams for critical reading of the manuscript.

Allen E. Greer, Jun.

Museum of Comparative Zoology,

Harvard University,

Cambridge,

Massachusetts 02138

JAmes D. LAZELL, JUN.

Massachusetts Audubon Society,

Lincoln,

Massachusetts 01773

RICHARD M. WRIGHT

Department of Biology,

Boston University,

2 Cummington Street,

Boston,

Massachusetts 02215

Received March 9, 1973.

${ }^{1}$ Frair, W., Ackman, R. G., Mrosovsky, N., Science, 177, 791 (1972).

${ }^{2}$ Mrosovsky, N., and Pritchard, P. C. H., Copeia, 624 (1971). 